\title{
CHARACTERIZATION OF PACKAGING GRADE PAPERS FROM RECYCLED RAW MATERIALS THROUGH THE STUDY OF FIBRE MORPHOLOGY AND COMPOSITION
}

\author{
S. ADAMOPOULOS* \\ E. MARTINEZ \\ D. RAMIREZ
}

Received: 15/12/05

Accepted: 29/03/06

\author{
AIDIMA (Wood, Furniture and Packaging Technology \\ Institute) \\ Technology Park of Valencia \\ 13 Benjamin Franklin \\ P.O.Box 50, 46980 Valencia, Spain
}

*to whom all correspondence should be addressed: e-mail: adamopoulos@teilar.gr

\begin{abstract}
The restrictions in availability of forest-based raw materials along with favourable environmental policies towards alternative sources of raw materials have forced corrugated packaging industry to shift towards recycled paper and other fibre sources such as non-wood and agro-residues. The variability in raw pulp materials with increasing percentages of recycled fibres is a very common technical problem for the corrugated packaging industry worldwide. Corrugating packaging production is facing the challenge to ensure a satisfactory strength of packages despite the increase of recycled paper as the main fibrous component. Sustainable manufacturing of papers of consistent and acceptable quality requests comprehensive characterization of the fibrous components, which are becoming more heterogeneous. Understanding the influence that heterogeneous recycled raw materials have on packaging grade paper properties offers great potential value to the corrugated board and packaging industry.

57 linerboards and corrugating medium were selected to represent all the variety of paper grades available on the market at the moment for the production of corrugated board in Spain. The papers were analyzed for their fibre morphology (fibre length, fibre width, lumen diameter, cell wall width and flexibility) and fibre composition (softwood to hardwood and nonwood fibre count and weight) and their strength (compression, bursting and crushing resistance) was evaluated. All the determinations were in accordance with the relevant TAPPI Test Methods. The significant differences found in most of the anatomical characteristics, fibre composition and strength properties among the paper grades reflected the diverse raw materials used for their production as well as their qualitative differences. By means of simple correlation the influence of fibre characteristics and composition on the strength of the papers was determined under two different conditions, at $23{ }^{\circ} \mathrm{C}$ and $50 \% \mathrm{RH}$ and at $20{ }^{\circ} \mathrm{C}$ and $90 \%$ $\mathrm{RH}$.

The results demonstrate that besides the physical-mechanical characterization of packaging grade papers, fibre anatomy and composition can be used successfully as a complementary practical test to predict the performance of papers. The application of the predicting correlations is proposed for the evaluation of the fibre supplies for the packaging industry. An enormous potential for cost reduction can be created by the selection of the most appropriate and inexpensive combination of grade papers for a specific packaging use.
\end{abstract}

KEYWORDS: recycled fibres, fibre properties, fibre composition, physical-mechanical characterization of paper, linerboard, corrugating medium, packaging.

*Present address: Technological Educational Institute of Karditsa, Department of Forestry and Management of Natural Environment, 43100 Karditsa, Greece. 


\section{INTRODUCTION}

The restrictions in availability of forest-based raw materials [1] along with favourable environmental policies (e.g. EU Packaging Directive 94/62/EC [2]) towards alternative sources of raw materials have forced corrugated packaging industry to shift towards recycled paper and other fibre sources such as non-wood and agro-residues [3-6]. The share of recycled paper is expected to increase significantly over the next years [7] and a consequence will be the change to more heterogeneous, numerous and smaller fibre sources for the packaging industry. Pulps from recycled paper consist of a mixture of paper grades and vary in composition from source to source and from day to day from a single source [8].

Most commercial pulps are produced with knowledge as to approximately which species or species groups are included and numerous studies have been carried out in order to understand the relationships between the characteristics of constituent fibres and paper properties [9-13]. This does obviously not apply to recovered pulps, which contain a mixture of several wood and non-wood fibre types that have been produced with a variety of pulping methods. The difficulty of predicting the properties of paper and paper products from recovered pulps puts several limitations in their effective utilization [14]. Nowadays, packaging grade papers contain $60-100 \%$ recycled fibres. Together with cleanliness of the pulp, the morphological properties of the recycled fibres are the greatest concerns of paper recycling [15-16]. Recycled fibres tend to be broken or damaged and they have different physical properties than virgin fibres (e.g. micro-fibrils on the surface of fibres tend to be collapsed) resulting to weaker inter-fibre bonding and consequently to lower strength in paper [17-21]. The use of modern process technology (mechanical refining, coatings, deinking, bonding adhesives etc.) and, thus, additional cost is necessary to compensate for inherent disadvantages of recycled fibres.

Corrugating packaging production is facing the challenge to ensure a satisfactory strength of packages despite the increase of recycled paper as the main fibrous component. An enormous potential for cost reduction can be created by the selection of the most appropriate and inexpensive combination of grade papers for a specific packaging use. A step towards this can be the identification of the effects of different types and morphological characteristics of fibres from recycled pulps on the quality of packaging grade papers, which are up till now not well documented. In recent work a blend of fibres recovered from municipal solid waste and old corrugated containers proved suitable for the production of corrugating medium but the necessity of further research was underlined in order for mills to be able to use less expensive combinations of raw materials [22].

Having in mind the need of corrugated board and packaging industry to evaluate their heterogeneous sources of fibre supply and to utilise the available resources in an optimal manner, we found appropriate to investigate the relationship between fibre characteristics (morphology and composition) and crucial strength properties of a variety of papers used as linerboard and corrugating medium for corrugated board manufacturing.

\section{MATERIALS AND METHODS}

\subsection{Sample selection}

57 different packaging grade papers were selected as to cover all the variety of papers, linerboards and corrugating medium available on the market at the moment for the production of corrugated board. The papers were supplied by several corrugated board manufacturers across Spain. The characteristics of the papers are shown in Table 1. Kraft-liner is mainly made from virgin softwood and hardwood fibres but also includes some recycled fibres (e.g. clippings from corrugated board manufacture or from old corrugated containers). Test-liner consists mainly of selected recycled fibres that increase the quality of the sheet. Recycledliner is made from recycled fibres and it is of lower quality than Test-liner. Semi-chemical is a virgin-based corrugating medium and is increasingly used for special purposes, for example, in humid conditions. The main virgin fibre used in manufacture is semi-chemical hardwood but lately recycled fibres have also been used. Recycled-medium is the multipurpose medium most frequently used and represents the lowest grade, which has been heavily recycled. 
Table 1. Paper characteristics.

\begin{tabular}{lcc}
\hline \multicolumn{1}{c}{ Paper grade } & Number of samples tested & Production technology \\
\hline $\begin{array}{l}\text { Linerboards } \\
\text { Kraft-liner } \\
\text { Test-liner }\end{array}$ & 15 & $\begin{array}{c}\text { Mainly virgin kraft fibres } \\
\text { ply of kraft-liner quality \& } \\
1 \text { ply of recycled fibres } \\
\text { Recycled fibres }\end{array}$ \\
$\begin{array}{l}\text { Recycled-liner } \\
\text { Corrugating medium } \\
\text { Semi-chemical }\end{array}$ & 8 & $\begin{array}{c}\text { Mainly virgin } \\
\text { Recycled-medium }\end{array}$ \\
\hline
\end{tabular}

\subsection{Fibre anatomy and composition}

Three values were calculated for a fibre length test according to TAPPI T $232 \mathrm{~cm}-01$ : the average weighted fibre length AWFL, the length weighted fibre length LWFL and the weight weighted fibre length WWFL. Fibre width FW and lumen diameter LD were measured in 200 fibres from each paper by light microscopy with a magnification of 400X. Cell wall thickness $2 \mathrm{CW}$ was obtained by subtracting lumen diameter from fibre width. From these values, the flexibility coefficient FC $(100 \times \mathrm{LD} / \mathrm{FW})$ and the L/T ratio (AWFL/2CW) were computed as a measure of fibre flexibility [23].

Fibre composition of papers on the basis of softwood versus hardwood and non-wood content was determined by standard fibre analysis according to TAPPI T $401 \mathrm{om}-03$. Due to the great variety of wood and non-wood species in the papers, the fibres were classed only into two categories: the softwood category and the hardwood and non-wood category. In that manner the correlation of fibre composition with paper properties was simplified and of more relevance. For those two categories, average weight factors were assigned to each paper to represent the combination of all the genera and species present. Identification of genera and species was made on the basis of structural characteristics of cells with the combined assistance of various keys [24-25] and textbooks with illustrations [26-29]. The weight factors used in this study for the calculation of weight percentages of the fibre categories are predetermined literature values taken largely from Einspahr and Hankey [30]. From the results taken from fibre analysis of papers the following ratios were calculated: the softwood to hardwood and non-wood fibre count (S/HN FC) and the softwood to hardwood and nonwood weight (S/HN W).

\subsection{Paper testing}

Samples were conditioned and preconditioned according to TAPPI T 402 om-03, with samples collected according to TAPPI T 400 om-02. The routine analyses on a number of industrial relevant physical tests included the following: grammage, thickness, compressive strength (Short span compressive test SCT), bursting strength and crushing resistance of corrugating medium (CMT test).

All the determinations were in accordance with the relevant TAPPI Test Methods. The above properties are most frequently requested by the industry for the assessment of the strength and quality of the papers.

\section{RESULTS AND DISCUSSION}

\subsection{Fibre characterisation}

Figure 1 shows typical microscope fields on a slide prepared from a Recycled-liner $(A)$ and a Recycled-medium (B). The presence of a large variety of different kinds of fibres and fibre fragments made fibre classification and counting a rather perplexing task.

Table 2 presents the mean values on fibre morphology and composition in the different grades of packaging papers, as compared to each other. The great differences found in most of the anatomical characteristics (except for the cell wall thickness) between the paper grades reflected the diverse raw materials used for their production. 


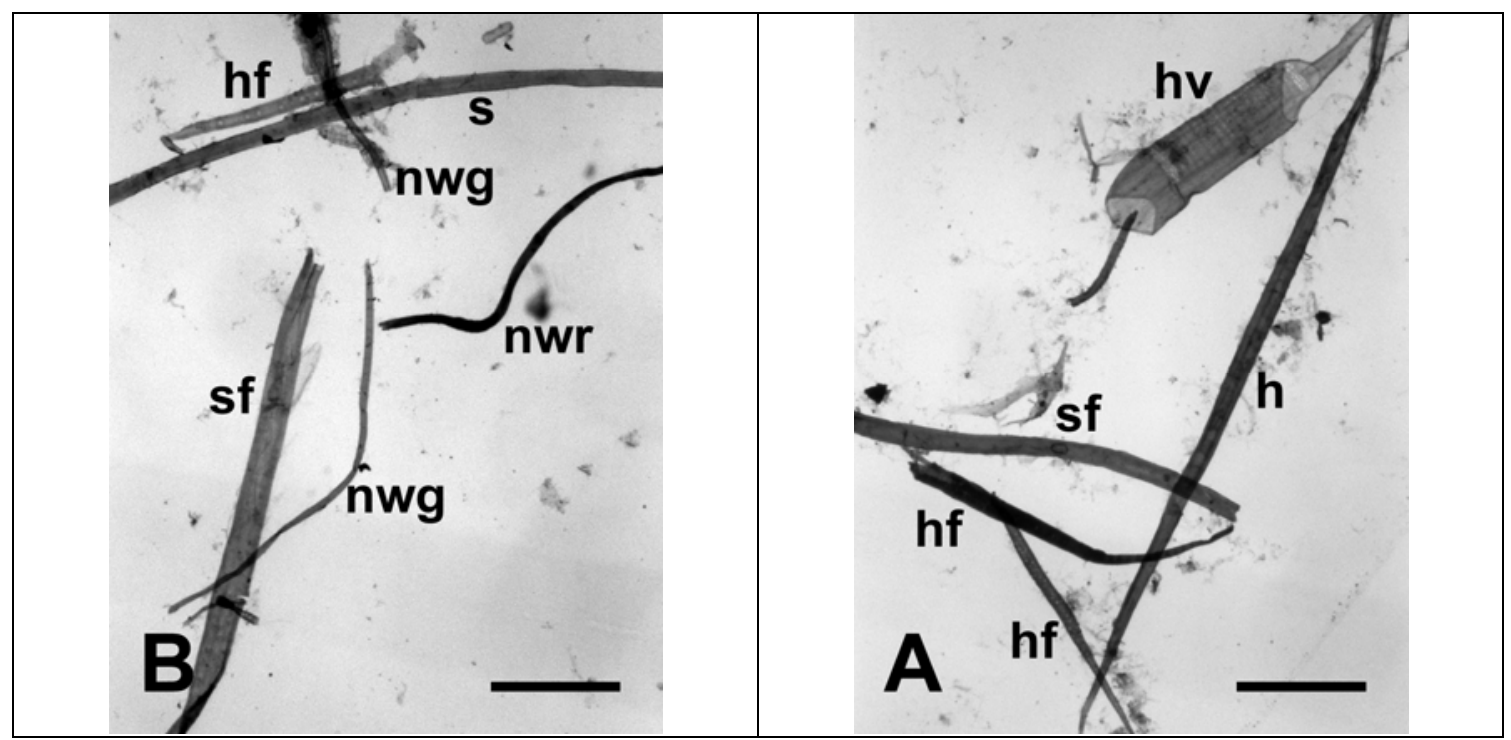

Figure 1. Examples of fibre classification in a Recycled-liner (A) and a Recycled-medium (B).

$\mathrm{h}$, hardwood fibre; hf, fragment of a hardwood fibre; hv, hardwood vessel element (in this case from Populus) counted also as a fibre; s, softwood fibre; sf, fragment of a softwood fibre; nwg, non-wood fibre (grass); nwr, non-wood fibre (rag).

Scale bars $=180 \mu \mathrm{m}$

Kraft-liners and Test-liners had the highest values but the difference from the other grades was not large. Since arithmetical averages cannot precisely represent the real situation in a pulp, we obtained significant information on the anatomical differences between the paper grades from the fibre length values. An interesting outcome was that although the average weighted fibre length was not much different between the papers (varied from $0.91 \mathrm{~mm}$ in Recycled-liners to $1.08 \mathrm{~mm}$ in Kraft-liners), we calculated much higher length weighted and weight weighted averages for the Kraft-liner and Test-liner grades. That implied that in those grades the short fibre elements and broken fibres compose a smaller weight fraction of the total pulp than the recycled based (liner and medium) for example and consequently contribute less to the total measured fibre length. Kraft-liner grade containing a significant amount of virgin fibres exhibited the highest length weighted $(1.64 \mathrm{~mm})$ and weight weighted fibre length $(2.42 \mathrm{~mm})$.

Table 2. Mean values of fibre measurements and composition.

\begin{tabular}{lccccc}
\hline \multirow{2}{*}{ Fibre properties } & \multicolumn{3}{c}{ Linerboards } & \multicolumn{2}{c}{ Corrugating medium } \\
\cline { 2 - 6 } & $\begin{array}{c}\text { Kraft- } \\
\text { liner }\end{array}$ & $\begin{array}{c}\text { Test- } \\
\text { liner }\end{array}$ & $\begin{array}{c}\text { Recycled- } \\
\text { liner }\end{array}$ & $\begin{array}{c}\text { Semi- } \\
\text { chemical }\end{array}$ & $\begin{array}{c}\text { Recycled- } \\
\text { medium }\end{array}$ \\
\hline Fibre length, mm & & & & & \\
AWFL & 1.08 & 1.03 & 0.91 & 0.94 & 0.96 \\
LWFL & 1.64 & 1.58 & 1.36 & 1.21 & 1.43 \\
WWFL & 2.42 & 2.25 & 2.00 & 1.59 & 2.04 \\
Fibre width FW, $\mu \mathrm{m}$ & 28.09 & 28.52 & 25.65 & 25.60 & 27.16 \\
Lumen diameter LD, $\mu \mathrm{m}$ & 21.24 & 21.67 & 19.07 & 19.03 & 20.36 \\
2CW, $\mu$ m & 6.85 & 6.85 & 6.59 & 6.57 & 6.80 \\
Flexibility coef. FC & 70.9 & 71.9 & 69.7 & 70.5 & 70.0 \\
L/T ratio & 177.8 & 162.0 & 145.9 & 153.4 & 150.8 \\
S/HN FC & 0.74 & 0.79 & 0.52 & 0.24 & 0.61 \\
S/HN W & 1.44 & 0.92 & 0.47 & 0.25 & 0.62 \\
\hline
\end{tabular}

The differences in average fibre dimensions between the packaging grades can be also explained by their structure as it is represented by their compositional analysis on the basis of softwood to hardwood and non-wood fibre count and weight. Kraft-liners and Test-liners were found to contain more softwood fibres in their furnishes than the other grades both in number (ratios 0.74 and 0.79 , respectively) and weight percentage (ratios 1.44 and 0.92 , respectively) 
contributing to their higher average fibre dimensions. The low presence of long and wide softwood fibres in the Semi-chemicals ( 0.25 softwood to hardwood and non-wood weight ratio) resulted in their lowest average fibre dimensions among the grades.

\subsection{Paper properties}

Table 3 summarizes the overall compression, bursting and crushing strength properties of packaging grade papers at the standard conditions of $23{ }^{\circ} \mathrm{C}$ and $50 \% \mathrm{RH}$.

Table 3. Paper properties (mean values) at $23{ }^{\circ} \mathrm{C}$ and $50 \% \mathrm{RH}$.

\begin{tabular}{|c|c|c|c|c|c|}
\hline \multirow[b]{2}{*}{ Paper properties } & \multicolumn{3}{|c|}{ Linerboards } & \multicolumn{2}{|c|}{ Corrugating medium } \\
\hline & $\begin{array}{l}\text { Kraft- } \\
\text { liner }\end{array}$ & $\begin{array}{l}\text { Test- } \\
\text { liner }\end{array}$ & $\begin{array}{l}\text { Recycled- } \\
\text { liner }\end{array}$ & $\begin{array}{c}\text { Semi- } \\
\text { chemical }\end{array}$ & $\begin{array}{l}\text { Recycled- } \\
\text { medium }\end{array}$ \\
\hline Grammage, $\mathrm{g} \mathrm{m}^{-2}$ & $185-298$ & $124-131$ & $112-152$ & $151-172$ & $91-111$ \\
\hline Thickness, mm & $\begin{array}{c}0.258- \\
0.437\end{array}$ & $\begin{array}{l}0.191- \\
0.208\end{array}$ & $\begin{array}{c}0.182- \\
0.228\end{array}$ & $0.221-0.271$ & $0.144-0.189$ \\
\hline $\mathrm{SCT}, \mathrm{kN} \mathrm{m}^{-1}$ & & & & & \\
\hline Machine direction & 8.79 & 4.05 & 3.67 & 6.47 & 3.18 \\
\hline $\begin{array}{l}\text { Cross direction } \\
\text { Compression index } \mathrm{Cl}, \mathrm{N} \mathrm{m} \mathrm{g}^{-1}\end{array}$ & 4.78 & 2.32 & 2.02 & 3.64 & 1.79 \\
\hline Machine direction & 36.9 & 32.6 & 28.0 & 39.8 & 30.8 \\
\hline Cross direction & 20.2 & 18.7 & 15.3 & 22.4 & 17.3 \\
\hline Bursting strength $\mathrm{BS}, \mathrm{kPa}$ & 937 & 410 & 266 & - & - \\
\hline Bursting index $\mathrm{Bl}, \mathrm{N} \mathrm{m} \mathrm{g}^{-1}$ & 4.0 & 3.3 & 2.0 & - & - \\
\hline CMT, N & - & - & - & 421 & 187 \\
\hline
\end{tabular}

As expected, the average strength values varied greatly between the paper grades reflecting their differences in quality. For example, in the linerboards the high quality stiff Kraft-liners have significantly higher average bursting strength $(937 \mathrm{kPa})$ than the Test-liners $(410 \mathrm{kPa})$ and the Recycled-liners $(266 \mathrm{kPa})$. In the same way, the crushing resistance of Semichemicals is much higher $(421 \mathrm{~N})$ than the Recycled-medium grade $(187 \mathrm{~N})$ respectively, which represents the lowest quality of corrugating medium. However, in recent years the increasing use of recycled fibres also in the virgin-based Kraft-liners and Semi-chemicals is diminishing the differences between the different grades regarding their strength properties. In some cases the compositional analysis on the basis of pulping processes of fibres is requested from paper microscopists and helps corrugated board manufacturers to verify the paper grade as the strength tests do not give us sufficient information. In this perspective, there is a need for advanced methods for a better prediction of the strength properties of packaging grade papers based on the evaluation of their heterogeneous raw pulp materials. This will lead to lowering the materials cost significantly while ensuring product quality. In order to cover specific packaging uses in humid conditions of Kraft-liner and Semi-chemical grade, their properties were determined at $20{ }^{\circ} \mathrm{C}$ and $90 \% \mathrm{RH}$ (see Table 4).

Table 4. Paper properties (mean values) at $20^{\circ} \mathrm{C}$ and $90 \% \mathrm{RH}$.

\begin{tabular}{lcc}
\multicolumn{1}{c}{ Paper properties } & Kraft-liner & Semi-chemical \\
\hline Grammage, $\mathrm{g} \mathrm{m}^{-2}$ & $200-321$ & $158-182$ \\
Thickness, mm & $0.278-0.457$ & $0.225-0.282$ \\
SCT, $\mathrm{kN} \mathrm{m} \mathrm{m}^{-1}$ & & \\
Machine direction & 4.02 & 3.05 \\
Cross direction & 2.26 & 1.86 \\
Compression index Cl, $\mathrm{N} \mathrm{m} \mathrm{g}^{-1}$ & 15.7 & \\
Machine direction & 8.9 & 17.4 \\
Cross direction & 786 & 10.6 \\
Bursting strength BS, $\mathrm{kPa}^{-1}$ & 3.1 & - \\
Bursting index BI, N m g & - & 226 \\
CMT, N & & \\
\hline
\end{tabular}




\subsection{Influence of furnish characteristics on strength paper properties}

The fibre morphological and compositional data and the data on the paper strength properties were subjected to a simple correlation analysis. This analysis helped us to identify the most significant relationships both from a useful and statistical or argumentative standpoint between fibre characteristics and paper properties. Our intention was by simple means to predict a single paper property using only one variable of the fibre furnish to facilitate acceptance by the industry. As it was considered impractical to record all the relationships tested in the investigation, since many of them were of little significance or were not statistically significant as mentioned before, the best correlations for evaluating the influence of furnish characteristics on the properties of packaging grade papers at $23{ }^{\circ} \mathrm{C}$ and $50 \% \mathrm{RH}$ and at $20{ }^{\circ} \mathrm{C}$ and $90 \% \mathrm{RH}$ were selected. The correlation coefficients for the two different testing conditions are presented in Tables 5 and 6, respectively.

The compression strength at $23{ }^{\circ} \mathrm{C}$ and $50 \% \mathrm{RH}$ proved to be a difficult property to predict and we were able to establish just three relationships and only for the machine direction (see first column of Table 5). The SCT value was positively related with the average weighted fibre length, the L/T ratio and the softwood to hardwood and non-wood weight. As these parameters are influenced largely by the presence of softwood fibres, an increase of the softwood content in the fibre furnish would lead to an increase of the SCT value in the machine direction. In the cross direction, the compression index was related negatively to a number of fibre characteristics and the correlations involving cell wall thickness and softwood to hardwood and non-wood fibre count were of the best significance. Reasonable means of predicting the influence of fibre characteristics and composition on bursting strength of linerboards were established. Specifically, positive slopes with an $\mathrm{R}$ value above 0.8 , which was statistically highly significant for fibre length (AWFL, LWFL, WWFL), L/T ratio and softwood to hardwood and non-wood weight, were obtained. Bursting index was also highly related (positively) with the weight weighted fibre length and the L/T ratio. The crushing resistance of corrugating medium (Semi-chemical and Recycled-medium) can be predicted remarkably well ( $R$ value 0.9 ) by the positive influence of lumen diameter.

Table 5. Correlation coefficients for evaluating the properties of packaging grade papers at $23^{\circ} \mathrm{C}$ and $50 \% \mathrm{RH}$.

\begin{tabular}{|c|c|c|c|c|c|}
\hline \multirow{2}{*}{ Fibre properties } & \multicolumn{5}{|c|}{ Strength properties } \\
\hline & $\mathrm{SCT}_{\mathrm{MD}}$ & $\mathrm{Cl}_{\mathrm{TD}}$ & BS & $\mathrm{BI}$ & CMT \\
\hline AWFL & 0.593* & & $0.801^{*}$ & & \\
\hline LWFL & & $-0.527^{*}$ & $0.821^{*}$ & & \\
\hline WWFL & & & $0.905^{\star \star}$ & $0.853^{*}$ & \\
\hline FW & & $-0.561^{*}$ & & & \\
\hline LD & & $-0.544^{\star}$ & & & $0.900 *$ \\
\hline $2 \mathrm{CW}$ & & $-0.629 *$ & & & \\
\hline $\mathrm{L} / \mathrm{T}$ & $0.693^{\star \star}$ & & $0.951^{* \star}$ & $0.845^{*}$ & \\
\hline S/HN FC & & $-0.651^{* *}$ & & & \\
\hline S/HN W & $0.566^{*}$ & $-0.587^{\star}$ & $0.843^{*}$ & & \\
\hline
\end{tabular}

* Correlation is significant at the 0.05 level (2-tailed).

${ }^{* *}$ Correlation is significant at the 0.01 level (2-tailed).

Under the humid conditions of $20{ }^{\circ} \mathrm{C}$ and $90 \% \mathrm{RH}$ we obtained statistical information that relates positively the fibre characteristics to compression strength of Kraft-liner and Semichemical grades (Table 6).

Although we know that those two grades have a different function in a combined corrugated board and that the demands on strength are different, we chose to investigate the influence of their totally diverse furnishes on paper properties. Taking also into account the fact that there is a trend of using recycled fibres (softwood, hardwood and non-wood) in the manufacturing of the Semi-chemicals in a way that they are not composed exclusively by virgin hardwood fibres and that the influence of fibre morphology is always the same independently the source, we found appropriate this grouping. Among the factors of Table 6 (that included AWFL, FW, LD, 2CW, S/HN FC 
and S/HN W), softwood to hardwood and non-wood weight was the best factor for explaining the SCT value in the machine direction ( $R$ value approaching 0.8 ).

Table 6. Correlation coefficients for evaluating the properties of packaging grade papers at $20^{\circ} \mathrm{C}$ and $90 \% \mathrm{RH}$.

\begin{tabular}{|c|c|c|c|}
\hline \multirow{2}{*}{ Fibre properties } & \multicolumn{3}{|c|}{ Strength properties } \\
\hline & $\mathrm{SCT}_{\mathrm{MD}}$ & $\mathrm{SCT}_{\mathrm{TD}}$ & $\mathrm{Cl}_{\mathrm{TD}}$ \\
\hline AWFL & $0.772^{*}$ & $0.813^{*}$ & \\
\hline LWFL & & $0.747^{*}$ & \\
\hline FW & $0.772^{*}$ & $0.947^{\star \star}$ & $0.939 * \star$ \\
\hline LD & $0.764^{*}$ & $0.944^{\star *}$ & $0.947^{\star \star}$ \\
\hline $2 \mathrm{CW}$ & $0.717^{*}$ & $0.820^{*}$ & $0.712^{\star}$ \\
\hline FC & & $0.790^{*}$ & $0.878^{\star *}$ \\
\hline S/HN FC & $0.726^{*}$ & $0.921^{* *}$ & $0.839 * \star$ \\
\hline S/HN W & $0.794^{*}$ & $0.889 * *$ & $0.733^{*}$ \\
\hline
\end{tabular}

* Correlation is significant at the 0.05 level (2-tailed).

${ }^{\star *}$ Correlation is significant at the 0.01 level (2-tailed).

From almost the same factors (plus the length weighted fibre length and the flexibility coefficient) we could predict the SCT value in the cross direction while R values were in general better. The compression index of Kraft-liners and Semi-chemicals in the cross direction at $20{ }^{\circ} \mathrm{C}$ and $90 \% \mathrm{RH}$ had a considerable relationship with the fibre dimensions and composition. In the latter conditions, the compression index increases mainly with the increase of width ( $R$ value 0.939) and lumen diameter ( $R$ value 0.947 ) of the constituent fibres. The bursting strength of Kraft-liners as well as the crushing resistance of Semichemicals at $20{ }^{\circ} \mathrm{C}$ and $90 \% \mathrm{RH}$ did not show any significant relationship with the morphological features of fibres and composition. A possible explanation could be the small number of samples tested (15 and 11, respectively).

The results from this study are indicative and help us understand the influence of furnish properties on paper strength. It is clear that the majority of the differences in the strength values between the packaging grades are not only due to the fibre characteristics, but also to the grammage variations and, more likely, to their interrelation. However, the results can be used as a basis for future experiments on paper grades produced by different fibre blends at a constant target grammage with all manufacturing parameters controlled (dry strength additives, wet pressing variables and forming variables).

\section{CONCLUSIONS}

As packaging grade papers incorporate a great variety of fibre types due to the increasing recycling rates set by environmental policies, the projection of the effects of those variable fibrous materials on the strength characteristics of the papers obtained in this study is of importance for a continual control of packaging fibre sources.

In practical industrial testing a number of tests are currently used in order to assess the quality of packaging grade papers on the basis of their physical-mechanical characteristics. The results demonstrate that fibre anatomy and composition can be used as complementary factors to evaluate the performance of papers. The prediction of strength behaviour of papers from simple correlations, which are easy to be adopted by the industry using as less variables of the fibre furnish as possible, can create an enormous potential for cost reduction. This will allow selecting the most appropriate and cost-effective raw pulp materials for a specific packaging use.

The statistical information provided in this study can be used as a basis for the development of diagnostics assessing the potential quality distribution of fibres from different sources. Additionally, we could use this method for the traceability assessment in the pulp-papercardboard chain. However, more research is needed especially on the actual pulps used for the manufacturing of the papers as well as on separate paper grades (establishment of chronological data on the fibre properties and composition, estimation of the quality of papers, projection of changes in fibre composition and anatomy on paper's performance, etc.). 


\section{ACKNOWLEDGEMENT}

The research was funded by a Marie Curie Postdoctoral Fellowship of the European Union (contract number HPMD-CT-2000-00043, project coordinated by Prof. Dr. José-Vicente Oliver).

\section{REFERENCES}

1. FAO (2001) Global Forest Resources Assessment 2000 Main Report, FAO Forestry Paper 140, Rome.

2. European Commission (1994) Council Directive of 20 December 1994 on packaging and packaging waste, 94/62/EC, Official Journal of the European Communities L365, 31.12.1994.

3. Mabee W.E. (1998) 'The importance of recovered fibres in global fibre supply', Unasylva, 49(193), 31-36.

4. Rowell R.M, Young R.A. and Rowell J.K. (1997) Paper and composites from agro-based resources, CRC Lewis Publishers, Boca Raton, FL.

5. Skog K.E., Ince P.J. and Haynes R.W. (1998) Wood fiber supply and demand in the United States, Proc. of the Forest Products Society Annual Meeting, June 23, Merida, Yucatan, Mexico.

6. Kramer J.D. (1998) Wood fibre supply - enough to match pulp and paper demand?, Proc. of the 1998 TAPPI Pulping Conference, TAPPI PRESS, Atlanta, p.31.

7. European Recovered Paper Council (2002) The European declaration on paper recovery, ERPC Annual report, Brussels.

8. Virtanen Y. and Nilson, S. (1993) Environmental impacts of waste paper recycling, International Institute for Applied System Analysis, Earthscan Publ. Ltd, London.

9. Dinwoodie J.M. (1965) The relationship between fiber morphology and paper properties: A review of literature, TAPPI J., 48(8), 440-447.

10. Horn R.A. (1974) Morphology of wood pulp fiber from softwoods and influence on paper strength, USDA For. Serv. Res. Pap. FPL 242, For. Prod. Lab., Madison, WI.

11. Horn R.A. (1978) Morphology of wood pulp fiber from hardwoods and influence on paper strength, USDA For. Serv. Res. Pap. FPL 312, For. Prod. Lab., Madison, WI.

12. Paavilainen L. (1991) Influence of morphological properties of wood fibers on sulfate pulp fibers and paper properties, Proc. of 1991 IPPC, Kona, Hawaii, 383-395.

13. Hunt J.F. (1998) New Developments In Molded Pulp Process \& Packaging II, Proc. of IMPEPA, Chicago, Illinois.

14. Abubakr S.M., Scott G.M. and Klungness J.H. (1995) Fiber fractionation as a method of improving handsheet properties after repeated recycling, TAPPI J., 78(5), 123-126.

15. Mckinney R.W.J. (1995) Technology of Paper Recycling, Glasgow, UK, 1995.

16. Law K.N. and Valade J.L. (1995) Use of sulphonated reclaimed fibers from newspapers in the manufacture of newsprint, Conference Technologique Estivale, Quebec, Canada, May 31 June 2, 39-48.

17. Eastwood F.G. and Clarke B. (1978) Fibre-water interaction in papermaking, Proc. of the BPBIF Symposium, Vol. II, London, U.K.

18. Howard R.C. and Bichard W.J. (1992) The basic effects of recycling on pulp properties, J. Pulp Paper Sci., 18(4), 151-159.

19. Scallan A.M. and Tigerstrom A.C. (1992) Elasticity of the wet fiber wall: effects of pulping and recycling, J. Pulp Paper Sci., 18(5), 188-193.

20. Laivins G.V. and Scallan A.M. (1993) The mechanism of hornification of wood pulps, Proc. of the 10th Fundamental Research Symposium, Oxford, UK, 1235-1260.

21. Ince P.J. (2004) Fiber resources, In: Encyclopedia of Forest Sciences, Burley J., Evans J. and Youngquist J.A. (eds.), Elsevier Academic Press.

22. Ashley C.R. and Hodgson K.T. (2003) Papermaking properties and morphology of cellulose fiber recovered from municipal solid waste, TAPPI J., 2(10), 19-22.

23. Horn R.A. and Setterholm C.C. (1990) Fiber morphology and new crops, In: Advances in New Crops, Janick J. and Simon J.E. (eds.), Timber Press, Portland, OR, 270-275.

24. Panshin A.J. and de Zeeuw C. (1980) Textbook of wood technology, Ed.4, Mc-Graw-Hill, New York.

25. Strelis I. and Kennedy R.W. (1967) Identification of North American commercial pulpwoods and pulp fibers, University of Toronto Press, Toronto, Canada.

26. Carpenter C.H. and Leney T. (1952) 91 papermaking fibers, SUNY College of Forestry, Syracuse, NY.

27. Côte W.A. (1980) Papermaking fibers. A photomicrographic atlas, Syracuse University Press, Syracuse, New York. 
28. Parham R.A. and Gray R.L. (1990) The practical identification of wood pulp fibers, $2^{\text {nd }}$ ed., Tappi Press, Atlanta, GA.

29. Ilvessalo-Pfäffli M-S (1995) Fibre atlas: Identification of papermaking fibres, Springer Verlag, Berlin.

30. Einspahr D.W. and Hankey J.D. (1978) Improved weight factors for fiber analysis, TAPPI J., 61(12), 86-87. 